\title{
The quality of diabetic care in a London health district
}

J. S. YUDKIN, B. J. BOUCHER, K. E. SCHOPFLIN, B. T. HARRIS, H. R. CLAFF, N. J. D. WHYTE, B. TAYLOR, D. H. MELLINS, A. B. WOOTLIFF, J. G. SAFIR AND E. J. JONES

From the Department of Metabolism and Endocrinology, London Hospital Medical College

SUMMARY In order to assess the quality of care in a community-wide sample of diabetic patients, a study was performed on 217 such patients identified in three group practices in an east London health district. Only $46 \%$ of the patients were currently attending a hospital. In the two years before review, $64 \%$ of patients had had their blood pressure recorded and $59 \%$ had had retinal examinations. Levels of glycosylated haemoglobin were significantly higher in patients on insulin than in those on oral regimes $(P=0.0004)$. The mean level of glycosylated haemoglobin was higher in patients from Social Classes III, IV, and V than in patients from Social Classes I and II $(P=0.005)$, but there was no difference in level between those patients attending hospital and those attending their general practitioners after accounting for differences in these two populations $(P=0 \cdot 19)$. Over $50 \%$ of all diabetic patients in this study had levels of glycosylated haemoglobin which may indicate vulnerability to microvascular disease.

During the last year, a scheme for shared diabetic care has been initiated by GPs and hospital diabetologists in the east London health district of Tower Hamlets. In order to assess the efficacy of this scheme, a pilot study is being conducted in three group practices, which together cover about one-sixth of the total population of the health district. For the pilot study, we have attempted to identify all the diabetic patients in these practices. We have collected demographic and clinical data on these patients, and assessed the overall quality of blood-glucose control by estimation of the levels of glycosylated haemoglobin. ${ }^{12}$ The data will provide a baseline for studies of the efficacy of the new diabetic scheme. However, they have also presented a unique opportunity to assess the current quality of care in a community-wide sample of diabetic patients, many of whom are not usually seen in hospital clinics.

\section{Method}

The three practices used for the survey comprise nine GPs. Each practice had a diagnostic register which helped in the identification of diabetic patients. In addition, the GPs listed any other diabetic patients seen during a six-month period. The hospital notes and practice records were searched for details of any diabetic complications which had been looked for and recorded during the previous two years. A letter was sent to all the patients asking them to attend the surgery to have blood taken. At these attendances, patients were asked for details of their occupations, which were categorised according to the Registrar General's classification. ${ }^{3}$ They were also asked about their current and past consumption of alcohol and tobacco. A single blood sample was taken into a potassium EDTA bottle for estimation of glycosylated haemoglobins by the method of Welch and Boucher. ${ }^{4}$ Any patient who did not attend was visited at home during the subsequent three months by one of the authors.

Comparisons of data were performed using Student's $t$ test or, where there were more than two groups, analysis of variance. If the distribution for two groups was not Gaussian (normal), the Mann-Whitney U-test was employed. Simple linear regression analysis, or Spearman rank correlation, was used for normal or non-normally distributed data respectively. In order to assess the relative importance of several interrelated variables, an analysis of variance and covariance was performed using the ANOVA programme of the Statistical Package for the Social Sciences. ${ }^{5}$ Comparisons of prevalence in subgroups of patients were made using $\chi^{2}$. In instances where there were more than two subgroups and a trend was suspected, the Kendall tau-C test was employed. Results are expressed as mean \pm SEM. A value for $P$ of less than 0.05 was considered as statistically significant. 


\section{Results}

DEMOGRAPHIC AND TREATMENT DETAILS

During the six-month period, 217 diabetic patients were identified in the three practices, representing $0.97 \%$ of the total practice lists. In the subsequent nine months, only four more patients have been identified, which suggests that the sample was almost complete.

Some of the characteristics of the diabetic population are shown in Table 1. A large proportion of the patients were first- or second-generation immigrants, both from Central Europe and from the New Commonwealth. Almost half of the patients were in Social Classes IV and V, a proportion slightly greater than for Tower Hamlets as a whole. ${ }^{6}$ Less than half of the patients were currently attending a hospital diabetic clinic $(n=100,46 \cdot 1 \%)$. Of the remaining 117 patients, $92(78.7 \%)$ had previously been receiving hospital diabetic care. It was not possible to tell from the records which patients had been discharged from the hospital and which had failed to attend. Patients in the care of GPs alone were significantly older than those attending hospital clinics. $(P=0.007)$. They were also more likely to have been recorded as suffering from heart disease $(P=0.007)$ and tended to be of lower social class $(P=0.04)$ than hospital patients, even when age differences were taken into account.

Just over half of all the patients in the survey were on oral hypoglycaemic agents, and one-fifth were on insulin. The remainder were on diet alone. The majority of patients on insulin (36 out of 44) were attending hospitals for diabetic care.

COMPLICATIONS

It was found that details of diabetic complications had not always been recorded in the GP and hospital notes during the previous two years (Table 2). In general, these details were more often available for patients attending hospitals than for those under the care of GPs. Furthermore, in some instances, details for these latter patients were obtained from old hospital notes.

Associations were sought between the prevalence of recorded complications and certain risk factors, although some caution is necessary in interpreting such findings. First, by the nature of the study, there was no standardised method of examining patients by a single observer. Secondly, because not all patients had been examined for each complication, the denominator population in each complication category was less than the total group. All recorded complications were more common with increasing age. The prevalence of diabetic eye disease and neuropathy also increased separately with increasing duration of diabetes. The prevalence of recorded ischaemic heart disease and peripheral vascular disease was significantly greater in Jewish patients than in other groups $(P=0.0002$ and $P=0.006$ respectively); these differences were not related to age difference or to differences in the frequency ${ }^{\circ}$ recording complications between the groups. Ther疱 was no correlation between the prevalence of ant complication and sex, social class, treatment, of tobacco or alcohol consumption, even when age and duration of diabetes were taken into account.

\section{GLYCOSYLATED HAEMOGLOBIN}

A blood sample for estimation of glycosylate haemoglobin was obtained from 214 of the $217 \%$ patients in the survey. The other three patients were abroad during the three-month period of blood sampling.

The mean value of glycosylated haemoglobin in these patients was $13 \cdot 31 \pm 0 \cdot 20 \%$, compared with an

Table 1 Demographic characteristics of diabetic patients in Tower Hamlets pilot study $(n=217)$

\begin{tabular}{|c|c|c|c|c|c|c|c|}
\hline RACE & $\begin{array}{l}\text { Caucasian } \\
\text { Asian } \\
\text { West Indian } \\
\text { Others }\end{array}$ & $\begin{array}{r}75 \cdot 6 \% \\
12.9 \% \\
8 \cdot 8 \% \\
2 \cdot 7 \%\end{array}$ & $\begin{array}{r}(164) \\
(28) \\
(19) \\
(6)\end{array}$ & - & $\begin{array}{l}\text { Jewish } \\
\text { Non-Jewish }\end{array}$ & $\begin{array}{l}30.4 \% \\
45.2 \%\end{array}$ & $\begin{array}{l}(66) \\
(98)\end{array}$ \\
\hline SOCIAL CLASS & $\begin{array}{l}\text { I and II } \\
\text { III } \\
\text { IV and V }\end{array}$ & $\begin{array}{r}9.3 \% \\
41.4 \% \\
49 \cdot 3 \%\end{array}$ & $\begin{array}{r}(20) \\
(90) \\
(107)\end{array}$ & & & & \\
\hline SEX & $\begin{array}{l}\text { Male } \\
\text { Female }\end{array}$ & $\begin{array}{l}49.3 \% \\
50.7 \%\end{array}$ & $\begin{array}{l}(107) \\
(110)\end{array}$ & & & & \\
\hline
\end{tabular}

Table 2 Frequency of recording of examination for diabetic complications during the previous two years

\begin{tabular}{llll}
\hline & $\begin{array}{l}\text { All patients } \\
(n=217)\end{array}$ & $\begin{array}{l}\text { Patients attending hospital } \\
(n=100)\end{array}$ & $\begin{array}{l}\text { Patients attending GP } \\
(n=117)\end{array}$ \\
\hline Blood pressure & $63.6 \%$ & $74 \cdot 0 \%$ & $54 \cdot 7 \%$ \\
Fundoscopic examination & $58.9 \%$ & $49.0 \%$ & $31 \cdot 9 \%$ \\
Peripheral nervous system & $47.0 \%$ & $66.0 \%$ & $30 \cdot 8 \%$ \\
Peripheral pulses & $41.9 \%$ & $61.0 \%$ & $25.6 \%$ \\
\hline
\end{tabular}


upper limit of normal of $10.5 \%$ in our laboratory. There was a weak positive correlation with duration of diabetes $(r=+0 \cdot 19, P=0.004)$ but age had no significant effect. There was a significant difference in the levels of glycosylated haemoglobin in the different treatment groups $(P=0.0004)$ : patients on diet alone $(12.74 \pm 0.44 \%, \mathrm{n}=51)$ and those on oral hypoglycaemics $(12.98 \pm 0.27 \%, n=120)$ had lower levels than those on insulin $(14.88 \pm 0.38 \%$, $n=43$ ). There was no significant difference in levels between those on once-daily and twice-daily insulin $(15 \cdot 15 \pm 0.42 \%$ vs $14.34 \pm 0.76 \% ; P=0.32)$.

Patients in Social Classes I and II had lower levels of glycosylated haemoglobin than those in Social Classes III to V $(11.40 \pm 0.64 \%, n=18$ vs $13.48 \pm 0.21 \%, n=196 ; P=0.005)$. There was no difference due to race in levels of glycosylated haemoglobin $(P=0 \cdot 11)$. However, there was a significant interaction between race and treatment, which indicated that Jewish patients are apparently poorly controlled on diet alone $(P=0.001)$ (Table $3)$. Smokers had significantly lower levels of glycosylated haemoglobin than non-smokers $(12 \cdot 80 \pm 0.32 \%$ vs $13.66 \pm 0.26 \% ; P=0.04)$ but alcohol consumption had no effect on these levels.

Table 3 Levels of glycosylated haemoglobin according to race and treatment

\begin{tabular}{lll}
\hline & Diet alone & Oral hypoglycaemics \\
\hline Jewish & $13 \cdot 25 \pm 0.63 \%(\mathrm{n}=23)$ & $12 \cdot 26 \pm 0.51 \%(\mathrm{n}=34)$ \\
Non-Jewish & $12.32 \pm 0.60 \%(\mathrm{n}=28)$ & $13.27 \pm 0.31 \%(\mathrm{n}=86)$ \\
\hline
\end{tabular}

Overall significance by analysis of covariance $P=0.001$.

Once again, as noted earlier, caution must be exercised in interpreting any association or lack of association between levels of glycosylated haemoglobin and the presence of complications recorded in the case notes. However, the levels of glycosylated haemoglobin in patients known to have diabetic retinopathy were higher than in patients known to be free of this complication; the difference was significant only at the $10 \%$ level. No other complication was associated with a difference in these levels.

Of all the patients who were invited to attend for blood sampling, $118(54.4 \%)$ did so. The mean level of glycosylated haemoglobin in these patients $(12 \cdot 87 \pm 0 \cdot 29 \%)$ was lower than in those who were visited at home $(13.91 \pm 0.36 \%)(P=0.05)$. The non-attenders were more likely to have suffered a stroke than those who attended $(P=0.05)$ but there was no difference in age, race, treatment or other complications between the two groups.

There was no significant difference in the levels of glycosylated haemoglobin between those patients under the care of hospital clinics and those under their GP (Table 4). However, the patient populations in these two groups differed in several respects. When analysis of variance and covariance was performed to take these factors into account (Table 4) there was a slight improvement in the mean value for hospital patients and a deterioration in that for GP patients, but the difference still did not achieve significance.

Table 4 Levels of glycosylated haemoglobin according to place of diabetic supervision

\begin{tabular}{lcl}
\hline & Mean \pm SEM & $\begin{array}{l}\text { Means corrected for } \\
\text { social class, treatment, } \\
\text { age, and duration }\end{array}$ \\
\hline Attending hospital & $13.39 \pm 0.30 \%$ & $13.01 \%$ \\
Under care of GP & $13.24 \pm 0.28 \%$ & $13.57 \%$ \\
Significance of difference & $\mathrm{P}=0.71$ & $\mathrm{P}=0.19$ \\
\hline
\end{tabular}

The levels of glycosylated haemoglobin were in the normal range for $19 \%$ of hospital patients and $21.9 \%$ of patients under the care of GPs $(P=0.84)$. However, in $60 \%$ of hospital patients and $54.4 \%$ of GP patients, the levels of glycosylated haemoglobin exceeded $12.6 \%(P=0.41)$. This level of glycosylated haemoglobin corresponds to an oral glucose-tolerance test $2 \mathrm{~h}$ blood glucose of $11 \cdot 1$ $\mathrm{mmol} / \mathrm{l}(200 \mathrm{mg} / 100 \mathrm{ml})^{7}$ and may, therefore, represent the threshold for risk of microvascular disease. $^{8}$

\section{Discussion}

Many of the published studies of patients with diabetes mellitus use hospital outpatients as the denominator population. We have found that in three practices in Tower Hamlets, less than half of the diabetic patients currently attend a hospital. Other studies of diabetes mellitus in general practice have found that the proportion of patients regularly attending hospital clinics varies between $28 \%$ and $77 \% .^{9-11}$ The characteristics of patients in this study seen in hospitals and those seen by GPs differ in several respects. These findings suggest that, in order to be representative, future studies of management of patients with diabetes should include both groups of patients.

It is possible that the practices participating in this study are not typical of inner city primary care as a whole. For example, single-handed GPs or those without diagnostic registers may refer a greater proportion of their diabetic patients for hospital care. Nevertheless, it appears that both in hospital clinics, and perhaps even more so in general practice, surveillance for diabetic complications is done less frequently than seems ideal. Moreover, the quality of blood-glucose control in the majority of diabetic patients leaves much room for improvement. In this 
respect, patients on insulin and those in Social Classes III to V may benefit most from intervention programmes aimed at improving control. The estimation of levels of glycosylated haemoglobin may offer a useful clinical tool to select those patients who are most in need of careful assessment and support.

It is clear that the demands on the resources for diabetic care greatly exceed supply. In the Tower Hamlets health district, the provision in hospital clinics of optimal care for all diabetic patients would more than double the current hospital diabetic workload. In contrast, the establishment and assessment of a diabetic support service is intended to look at the feasibility and efficacy of encouraging a greater involvement of GPs and community services in the care of diabetic patients. In such a context, the facilities of the hospital would be used to supply educational and clinical support for the GPs and community nursing staff as well as for patients. ${ }^{12}{ }^{13}$ The data of this study will be used as a baseline to assess the possible benefits of the diabetic support service in terms of both blood-glucose control and the detection and management of complications.

We thank Dr. Simon Welch and Ms. Christine Swindlehurst for performing the estimations of glycosylated haemoglobin. We also thank Ms. Janet Baker for excellent secretarial assistance.

Reprints from Dr. J. S. Yudkin, Whittington Hospital, Archway Wing, Highgate Hill, London N19 5NF.

\section{References}

${ }^{1}$ Koenig RJ, Peterson CM, Jones RL, Saudek C, Lehrman $M$, Cerami A. Correlation of glucose regulation and haemoglobin $\mathrm{A}_{\mathrm{lc}}$ in diabetes mellitus. $N$ Engl $J$ Med 1976; 295: 417-20.

${ }^{2}$ Gabbay KH, Hasty K, Breslow JL, Ellison RC, Bunn HF, Gallop PM. Glycosylated haemoglobins and long-term blood glucose control in diabetes mellitus. $J$ Clin Endocrinol Metab 1977; 44: 859-64.

${ }^{3}$ Registrar General. Classification of Occupations. London: HMSO, 1970.

4Welch SG, Boucher BJ. A rapid micro-scale method for the measurement of haemoglobin $A_{1(a+b+c)}$. Diabetologia 1978; 14: 209-11.

${ }^{5}$ Nie NH, Hull CH, Jenkins JG, Steinbrenner K, Bent DH. Statistical Package for the Social Sciences. 2nd edn. New York: McGraw Hill, 1975.

'City and East London Area Health Authority (Teaching). Tower Hamlets Health District Plan 1979-1982. London: City and East London AHA, 1978.

${ }^{7}$ Boucher BJ, Welch SG, Beer M. Glycosylated haemoglobins in the diagnosis of diabetes mellitus. Clin Sci Mol Med 1979; 58: 21.

${ }^{8}$ Jarrett RJ, Keen H. Hyperglycaemia and diabetes mellitus. Lancet 1976; ii: 1009-12.

${ }^{\circ}$ Andrews CT. A survey of diabetes in West Cornwall. Br Med J 1957; i: 427-33.

${ }^{10}$ College of General Practitioners-Hull and East Riding Sub-Faculty. Diabetes mellitus in Hull and the East $\subseteq$ Riding of Yorkshire. J $R$ Coll Gen Pract 1960; 3: 468-74.

${ }^{11}$ Doney BJ. An audit of the care of diabetics in a group practice. J R Coll Gen Pract 1976; 26: 734-42.

${ }^{12}$ Hill RD. Running a diabetic clinic. Br J Hosp Med 1976; 16: $218-26$.

${ }^{13}$ Anonymous. Care of the diabetic: the hospital and the GP. Drug Ther Bull 1979; 17: 15-16. 